\title{
X Baltic-Nordic Agrometrics Conference: Mathematics and Statistics for the Sustainable Development
}

\author{
*Anna Vintere \\ Latvia University of Agriculture, Department of Mathematics, Lielā street 2, Jelgava, LV 3001, Latvia
}

\section{$\mathrm{X}$ Baltic-Nordic Agrometrics conference "Mathematics and Statistics Society for Sustainable Development" was held from 15 to 17 September at the Latvian University of Agriculture (LLU) in the framework of the Nordplus Higher Education 2016 project NPHE-2016/10342 "Raising awareness about the role of math skills in building specialists' competence for the sustainable development of society". Agrometrics is mathematics and statistics in agricultural science and studies.}

Agrometrics network has been going on since 1998, bringing the mathematicians and statisticians from the so-called Baltic and Nordic Agricultural Universities. Under this initiative, ten Nordic-Baltic Agrometrics conferences have already taken place: Kaunas, Lithuania (1998), Karaski, Estonia (199), Jelgava, Latvia (2001), Uppsala, Sweden (2003), Otepaa, Estonia (2005), Kaunas, Lithuania (2005) Jelgava, Latvia (2010), Tartu, Estonia (2012), Kaunas, Lithuania (2014) and Jelgava, Latvia (2016).

It is already a tradition that Agrometrics Conference organizers gather experience from previous years and put it on, thus keeping the idea of the Agrometrics network. The problems encountered and progress achieved in cooperation among the Baltic and Nordic countries so-called Agricultural universities in the area of Agrometrics has been assessed as well as outlined the future cooperation directions. The Baltic and Nordic Agrometrics network idea's essence is the following:

1) Identify what kind of mathematics education and to what extent is required for agriculture specialists;

2) Establish common standards in higher agriculture education with a view to promote the study programs coherence as an important factor for the common European education space,
3) Enhance the quality of mathematics learning and teaching through the exchange of lecturers' experience and review the use of learning methods and mathematical modelling techniques in agriculture.

The aim of the $\mathrm{X}$ Baltic-Nordic Agrometrics conference was to exchange ideas, find out new solutions or highlight topical problems on the mathematics, statistics, informatics and physics education tendencies, practical application and research in the context of sustainable development.

Integration of sustainable development into an educational system at all levels is an important challenge that has been encountered in recent years. The universities have a special responsibility to ensure sustainable development in their curricula, teaching practices, research and consulting, community service activities, institutional practices, promoting the achievement of sustainable futures embracing ecological, economic and social aspects of human existence. That poses new challenges also for mathematics and statistics education and research and outlines new directions for future development of Agrometrics network.

19 reports and 5 poster presentations were presented at the X Agrometrics conference plenary section and five working sections. On the first day of the conference the universities exchanged their experience, they presented their mathematics and statistics study programs, teaching methods, credit system, etc. There were also compared the results of the diagnostic tests in mathematics used for first year students. These tests were created in 2001 and all the network universities are increasingly fulfilling them, thus, providing opportunities to compare students' grounding in mathematics in the Baltic States.

Further work was organized according to the $\mathrm{X}$ Baltic-Nordic Agrometrics conference major themes:

\footnotetext{
* Corresponding Author's email: anna.vintere@1lu.lv
} 
- Mathematical competencies in the context of the society sustainable development;

- Mathematics and statistics courses content, didactics and study process organization;

- New technologies for learning and teaching;

- Mathematical modelling in agricultural research and teaching;

- The applications of mathematics in physics;

- Informatics role in the development of information literacy and interdisciplinary study process;

- Mathematics teachers' professional development;

- Mathematics education problems and solutions for nowadays school, university and adult education.

Conference participants' reports illustrated the role of mathematics in the sustainable development of society in all its aspects: environmental, economic and social. During the conference the scientists presented research on mathematics as a tool, which both describes the problems and provides the opportunity to examine the situation and make informed decisions as well as provide understanding of the world and its regularities. There were also presented various mathematical models, which allow you to plan resource utilization problems, make pollution control and predict the possible consequences.

Mathematics role in sustainable development is also very important from the aspect of competence. Therefore, during the conference there were a lot of discussion on both mathematics and statistics courses content as well as teaching methods and the organization of study process, because it is an important issue for all universities - how to organize the mathematics and statistics studies to develop the competencies needed for a sustainable society. In Latvia, this issue is particularly topical because by the 2020 the teaching of mathematics in schools will be transformed on competence-based learning process. That is why universities in due time have to seek for solutions. There were offered several solutions: to build joint inter-university courses on the applications of mathematics to develop students' ability to understand resource utilization problems (both for basic studies and for the master level), activate the students' research work in mathematics, introduce in the study process information technology-based innovations, etc.

During the conference it was recognized that much has been done in the sphere of cooperation in mathematics and statistics education and research. Yet, a lot of things still need to be done and discussed. Taking into consideration the mathematics role in the development of sustainable society as well as scientists' opinions on changes needed in mathematics and statistics studies programs as well as several organizational aspects of Agrometrics studies process e.g. the approaches to promote cognitive development of students, mathematics didactics, e-learning, cooperation of the agriculture education participant, promotion of the development of the competences, work with gifted students etc., as further areas of cooperation were identified:

- The work on joint interdisciplinary study programs;

- Gathering and promotion of the information on applied software in Agrometrics studies and research;

- The development of the common databases for the rural research;

- The collection of mathematical and statistical modelling methods used in agriculture and dissemination among Nordic-Baltic and other European so called Agriculture universities;

- The cooperation for developing statistical consultancy in Baltic countries;

- The sharing of teaching and learning experiences, etc.

In summary it should be noted that X BalticNordic Agrometrics conference "Mathematics and Statistics Society for Sustainable Development" has become a new milestone in the development of Agrometrics network:

1) In terms of content - launched the work on updating the mathematics and statistics role in the context of sustainable development;

2) In terms of organisation - regional universities are invited to join the Agrometrics network. In essence regional universities have also focus on rural development by region context.

Here are published selected reports of the $\mathrm{X}$ Baltic-Nordic Agrometrics conference "Mathematics and Statistics Society for Sustainable Development", thus, illustrating the mathematics and statistics topical issues of the Baltic States universities. 